\title{
Alice Mills \\ Neurolinguistic Programming and the Teaching of Creative Writing
}

Neurolinguistic programming (NLP) can be defined as an epistemology, a study of how people know and understand the world and themselves (DeLozier and Grinder 221; Dilts xix); as well as comprising a theoretical model inspired by hypnotherapy, neurology and linguistics, it offers practical tools for exploring and changing aspects of the psyche. Thus, in addition to offering answers to questions about how we know, it offers solutions to questions about how we can change what we understand about ourselves and the world. NLP has found its main applications to date in psychotherapy, business and education, in such seemingly diverse areas as the cure of phobias and the teaching of good spelling to adults with a long history of being chronically poor spellers. One of NLP's basic premises is that people are capable, if only they can find new tools and techniques and free themselves of any habits, beliefs and attitudes that are currently hindering them. NLP thus offers an essentially optimistic technology for change.

NLP originated, in practical terms, in the aspirations of its founders to model some extraordinarily successful psychotherapists, and thus to discover just what made them so successful and others, who seemed to be doing similar things, far less effective as therapists. The NLP practice of modelling the minute steps of successful practice has extended far beyond the field of psychotherapy, to include studies of highly creative artists and business people. It is the modelling of the creative artist that interests me in the application of NLP to the teaching of creative writing. Like Freudian theory, NLP takes into account both the psychopathology of everyday life, as Freud terms it, such curious human behaviours as selflimitation and self-sabotage, recurrent patterns of difficulty in one's life (such as writer's block), and it also takes into account the psychological workings of the extremely gifted. Freud himself studied and analysed Leonardo da Vinci's creativity; NLP goes further than Freud in offering practical applications for this kind of investigation. NLP claims that not only can a study of creative genius reveal aspects of the unconscious with peculiar clarity, but also that the steps taken by creative genius in the process of creating can be modelled and followed by others. This is not to promise that by taking the same kind of creative steps as a da Vinci or Mozart, one is guaranteed to compose or paint or invent as prodigiously as a da Vinci or a Mozart; but it is to offer a range of techniques that can help move other creative artists past any habits or beliefs that may be blocking them, and extend the range of creative practice beyond the familiar territory of habit. To try out the method of working which a Walt Disney or a Freud is recorded as having practised is to gain an opportunity to acquire consciously new methods of creating, which at the very least may prove effective against any previous sense of being blocked. 
I have given da Vinci, Mozart, Freud and Walt Disney as my examples not only because they span a wide field of creativity but because they are among the creative geniuses analysed by one of the leading theorists of NLP, Robert Dilts, in his three-volume study, Strategies of Genius. Dilts' intent in these books was to study the strategies which worked so well for these highly creative people in achieving the creative outcomes that they sought, and he also aims to demonstrate how these strategies can be applied to the reader's life and work. Dilts is not analysing the product, that is, the creative work, nor is he psychoanalysing the artist through the art. Rather, he takes as his evidence such material as letters, journals, biographical anecdotes, even portraits and sketches of the artist at work. He analyses this evidence to provide a series of steps, for instance of moving from a visual image to self-dialogue or from a bodily sensation to a visualisation, and so traces the different series of steps used by these creative geniuses to transform the first impulse, the ways in which they first manifested their idea, their characteristic processes and sequences of imagining, what they saw, felt, heard, and what they said to themselves about it as their creativity moved from potential to manifest outcome - just how they went from imagining something new to realising it, in such forms as a symphony or a painting, an animated film or a technological invention. Dilts models and analyses each creative process of an Aristotle or an Einstein or a Tesla, as far as the evidence permits, to work out their conscious and unconscious strategies for achieving their creative output, so that the reader can try out these sequences and thus extend their own repertoire.

Of the creative geniuses analysed by Dilts, none is known as a creative writer, but I have found his examples rather more helpful to my students than the more skills-oriented NLP study of writing skills, Dixie Hickman and Sid Jacobson's The Power Process: An NLP Approach to Writing (Hickman \& Jacobson 1997). This book offers a variety of practical advice to the writer, whether as essay-writing student, as creative writer or as generator of business documents, and it draws on the same kinds of epistemological models as Dilts' Strategies of Genius. What it lacks, however, is the minute analysis of the workings of a creative genius that function so well in Dilts' book to encourage the reader both to try out these steps and to become more conscious of their own creative process. Making use of Dilts' examples in my teaching of creative writing has the further advantage of holding out some most eminent models without putting the student to shame by comparison; this is possible because, like most NLP theorists, he analyses process rather than content.

I would like to give an example of using Dilts' Strategies of Genius in the teaching of creativity. One of the problems that several of my students and colleagues have consulted me about is to do with being over-critical of creative work in its early stages of gestation. Sometimes this problem manifests externally, when, for instance, a writer mentions a new project and is derided for it, long before it has been worked through to its final form - sometimes even before the first word has been written. The poor artist is left struggling with self-doubt, ready to relinquish the project. Sometimes the same problem manifests internally, as when a student tells me that he or she cannot finish - or cannot even begin - a piece of writing because of the savagely critical voice in their head telling them how worthless it all is. I could at this point start exploring the content of the new project, and give some emotional support to the distressed would-be writer, and sometimes the presence of a patient and non-judging listener is all that is needed to get past this point of stuckness. For others, however, this problem of becoming stuck at an early point in the creative process, 
paralysed by negative judgement, seems to be part of an often-repeated pattern. Here I find the NLP approach to process rather than content a particularly helpful intervention. Rather than analyse the malevolence of jeering auditors, an alternative strategy to deal with the problem is to tell my distressed student or colleague a story drawn from Dilts, which I have found very helpful in these cases.

According to Dilts, Disney excelled in three different stages of the creative process as exemplified in the practices of his studio: in the production of new ideas for his animated films and other works, in realising his projects step by step, and in evaluating the worth of each project. In my observation, it is unusual for one person to excel at all three stages; more often, someone may excel at what Dilts calls the 'dreamer' stage of coming up with new projects, but not have the skills and motivation to realise or judge the worth of these projects, or may be a talented realiser of other people's dreams without being a productive dreamer or judge, or may excel as critic and judge of others' projects without inaugurating or working through any such projects of their own. As educators, we tend to expect our creative writing students to gain at least a competency in all three areas, but are probably best equipped as scholars in the evaluative tradition of Western pedagogy to train our students in the arts of literary criticism. How, then, to reframe the pedagogical model so that judgement and evaluation are put to profit, rather than to inhibit, the creative process? This is the question to which Disney's working practices provide a helpful answer.

In Volume 1 of Strategies of Genius, Dilts analyses these three phases of creativity for the Disney studio, looking at the minute details of just how Disney fostered what Dilts terms the 'dreamer', the 'realist' and the 'critic' in the making of his animated films and other products. He comments, for instance, on the probability that in the dreamer stage, Disney was using synesthesia, and makes the point that in the realist stage, he initiated the practice of story-boarding a film. The critic phase was quite sharply differentiated from these other two: Dilts quotes one of Disney's animators as saying 'there were actually three different Walts: the dreamer, the realist and the spoiler' (Dilts 163). Disney set up a screening room in which the animators' work was assessed, a physically different space from the area in which the animators did their work of realising the concept. 'Disney's was the first studio to spend the time and money to film the initial black and white drawings of his animators and evaluate them before they went in to final production' (Dilts 178). Thus the judgement and evaluation came after the 'dreamer' had come up with the idea and the 'realist' had manifested the idea into a viewable product (but not at the very end of the process, when adverse judgement might cause enormous delays or the expense of abandoning a completely realised project).

As I describe the working arrangements of the Disney studio, I can (but usually do not find much need to) draw direct parallels with the situation that is vexing my student or colleague. The Disney story emphasises the helpfulness of the critic to the creative process, whether it be an internal or an external critic; it also emphasises the importance of bringing in the critic at the optimal points in the process, not too late and definitely not at the very beginning, when a creative idea is at its most vulnerable, while it exists only in the imagination. Dilts' analysis and application of Disney's three phases of creativity can be applied not only to the nagging voice in the writer's head or to the sneering comments of colleagues but also to the physical arrangement of working space. His example is that of a computer company 
I use this process in my own computer company. We have actually different rooms where we can go to think different ways: one to brainstorm, another to plan and another to evaluate. When we brainstorm we most often sit in a circle. But when we start planning we all sit next to each other and look at the plan on a board. And when we are evaluating we sit around a table with the plan in the center and ask: "Is this really going to work?" So you can also set up the environment to support a multi-person circuit as well. (Dilts 204-205)

This can easily be applied to the routine of a creative writer's process, by consciously differentiating the physical location of the realist phase from that of the critic or dreamer - one in the local café, perhaps, another sitting at the computer, another in the armchair reading through the manuscript. These are simple, practical steps with the potential to reframe the difficulties of judgement into an integral, highly valued step in the process of creative writing. (See Richard Bandler and John Grinder, Reframing [Bandler \& Grinder 1982], for a book-length analysis of this NLP process).

My second example of using NLP in the teaching of creative writing is also drawn from the NLP concept of modelling, but this time it is not the modelling of creative genius from the past but modelling from the student's own successes in a different creative field. Very often, people can be more than competent in their skills in some areas of creative endeavour but experience severe difficulties and self-doubts in another area. It would be rare to come across someone who lacked even one modest successful creative strategy. The teacher's skill here lies in eliciting and using it. Sometimes these successful strategies are easily observable from their outcomes: a person may have a gift of fluent ease in a social situation, or be a creative doodler, or demonstrate wit. Other successful creative strategies can be gleaned from what people disclose about themselves, as in the following case.

In casual conversation I learned that my student made most of her own clothes. To my eye she always looked elegantly dressed, her clothes beautifully cut and sewn and their colours and textures suiting her well. She came to me one day in distress about her writing style, which had become stiffer and more clumsy as she wrestled with applying the concepts of a French school of critical theory to the critical part of her current writing project. Her own writing was becoming contaminated, starting to read like a torturous translation from the French, and she was losing all her fluency and flair. I had to agree with her assessment of her own work; indeed, I had been wondering for some time just how I could help her improve her style again. As we talked, I remembered what she had told me about her clothes, and it occurred to me that this provided an excellent model for her prose style. She had in fact given me a powerful metaphor that I could elaborate upon as we kept talking. I reminded her of how easy she found it to choose a pattern that would suit her, how intuitively she knew what style of clothing would suit her, without any doubt. I spoke of her confidence and skill in laying out the pattern and cutting, probably making her own creative modifications to the overall shape of the clothes as she did so (she was nodding in agreement as I kept talking). I commented on her abilities in choosing colours and textures that would be perfect for the skirt or jacket that she was making, and that would complement one another so well. I acknowledged her skill in determining the perfect length for a skirt - she knew just when to cut it for 
the best effect, I said. Then I began relating all of this to her prose style, talking about fluency and flow, about how best to lay out an argument, when to modify, at what point to end a sentence or paragraph, how to achieve an elegant simplicity in the expression of subtle ideas. I did not elaborate on how to do these things, for in another domain she clearly knew very well how to do them. Instead, I invited her to model her own successes in the making of clothes onto the making of an exegesis. The outcome was an ever-increasing improvement in her prose style, with less and less obscurity or conscious straining for effect.

Like my NLP style conversations about Disney, my use of the clothes metaphor emphasised only the positive possibilities of the creative writing process. To help my students, I did not find it necessary to go into the distressing content of their experience. Rather, I found an inspiring model, a tactic that is particularly helpful in my experience when the model is oneself. If the student has not already provided the teacher with material from which such a model can be constructed, it is possible to ask for one, quite directly: is there some hobby, perhaps, that the student has, or what was the most fulfilling moment of their life. It is then up to the ingenuity of the teacher to elaborate this into the most helpful series of parallels to the student's current predicament (gardening provides a particular abundance of opportunities for unforced parallels). The advantage of using so visible a creative success as my student's elegance in dress is that whenever she is complimented again on her clothes, the model for elegance in her prose style will also be reinforced, whereas the use of, say, a happy childhood memory by the teacher is much less likely to function as one in a series of reinforcing compliments.

One way of developing the NLP skill of using therapeutic metaphor as a teacher of creative writing is to become more conscious of the metaphors already in common use with regard to the process of writing. Students give an abundance of opportunities for the building of helpful metaphor by the metaphors they themselves use in discussing the process of creative writing (building in this sentence is just such a metaphor, that could be used to develop a metaphor drawn from architecture). Weaving a tale opens possibilities for self-modelling for sewers, knitters and weavers. Painting a picture of landscape or making a character vivid is open to elaboration for artists to self-model. Pruning superfluous adjectives could be developed into a set of either visual or physical metaphors drawn from gardening, and a story's tempo lends itself to elaborated musical metaphor. Cooking up a plot could be put towards a therapeutic metaphor either of cooking or of enjoying a good meal. Playing with an idea has a host of possible applications. Even the dread writer's block is a metaphor that could be teased out in the language of sport or woodwork. (David Gordon discusses both the theory and practice of using such metaphors in a psychotherapeutic context in his 1978 Therapeutic Metaphors [Gordon 1978].)

All of the NLP techniques discussed in this paper intervene at the level of process, not content. With an NLP approach, the anguish felt by some students at their stuck state or at the negative comments passed by others on their proposed creative project, is acknowledged but not dwelt upon. Instead, the teacher looks for a positive reframing of what has occurred and uses only positive language, therapeutic metaphors and models either from the history of creative genius or from the student's own personal history of success. Helpful NLP intervention can seem as casual as a compliment on some seemingly unrelated aspect of a student's life, or can be as overtly directed as the spelling out of Disney's creative processes. In 
this respect, it is a supremely elegant addition to the pedagogic repertoire of the teacher of creative writing.

\section{References}

Bandler, Richard and John Grinder. Reframing: Neuro-Linguistic Programming and the Transformation of Meaning. Moab, Utah: Real People Press, 1982. Return to article

DeLozier, Judith and John Grinder. Turtles All the Way Down:

Prerequisites to Personal Genius. Snake Valley: Grinder and Associates, 1987. Return to article

Dilts, Robert. Strategies of Genius. Vol. 1. Cupertino, CA: Meta Publications, 1994. Return to article

Gordon, David. Therapeutic Metaphors. Cupertino, CA: Meta Publications, 1978. Return to article

Hickman, Dixie and Sid Jacobson. The Power Process: An NLP Approach to Writing. Carmarthen: Crown Publishing, 1997. Return to article

Alice Mills is associate professor of literature and children's literature at the University of Ballarat, where she is also course coordinator for the Diploma of Arts/Bachelor of Arts in Professional Writing and Editing. She has published widely as a literary critic and has edited a number of anthologies of literature for children as well as two scholarly books, on the grotesque and on the unspeakable. Her most recent book (as consultant editor) is Mythology: Myths, Legends \& Fantasie. Alice is also a psychotherapist and an NLP practitioner.

\section{TEXT}

Vol 8 No 2 October 2004

http://www.griffith.edu.au/school/art/text/

Editors: Nigel Krauth \& Tess Brady

Text@griffith.edu.au 